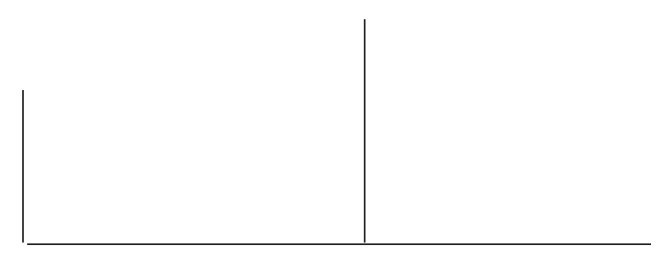

Rev. Latinoam. Psicopat. Fund., IV, 4, 92-102

\title{
A melancolia na obra de Freud: um Narciso sem [des]culpa
}

Ana Cleide Guedes Moreira

Este trabalho apresenta a problemática de definição da melancolia, examinada a partir da obra freudiana, no qual ela já está indicada desde o texto "Luto e melancolia" (1917). A abordagem da concepção freudiana conduz ao exame dos principais textos em que esta é formulada como uma neurose narcísica, derivada do recrudescimento do conflito edípico e envolvendo as fantasias de parricídio e incesto, a partir de uma perda objetal retirada da consciência.

Palavras-chave: Melancolia, depressão, narcisismo, parricídio 
Freud terminou de escrever "Sobre a introdução do conceito de narcisismo" em fevereiro de 1914, após uma viagem de férias para Roma onde o iniciara. No mesmo momento, começava a conceber "Luto e melancolia" (1917[1915]), só concluído em maio do ano seguinte. Ele costumava escrever, assim, trabalhos separados para problemas que ocupavam simultaneamente o mesmo espírito, este sim único. Mas não indiviso, como bem mostrou. $\mathrm{O}$ eu não é o senhor em sua própria casa: eis o que enunciou como a descoberta pela qual pensava que a psicanálise merecia seu lugar na história. De importância ímpar, a compreensão do narcisismo permitiu-lhe dirigir a visada às sombras que habitam, na melancolia, o mesmo cômodo, iluminando um enigma que vem atravessando há dois mil e quinhentos anos a civilização ocidental.

De fato, sua investigação da melancolia o acompanha desde a última década do século XIX, pelo menos. Desenrolase ao longo de sua obra com variada intensidade, mas sempre produzindo efeitos: são mais de cinqüenta obras de referência, entre artigos, ensaios, conferências, além das indicações e comentários distribuídos em cartas, especialmente a Fliess, Abraham, Ferenczi, e Marta, naturalmente. Essa investigação permitiu a elaboração de vários conceitos fundamentais da psicanálise, tais como identificação, ideal de ego, superego, ambivalência e sentimento inconsciente de culpa, para ficar nos mais importantes.

Há um longo caminho a percorrer para sustentar a hipótese que orienta este trabalho, mas diante dos limites 


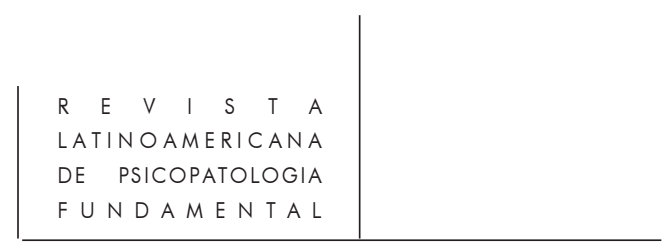

criados pelos objetivos que o motivam, ele tratará tão-somente de indicar em linhas gerais, as principais referências que o animam. ${ }^{1}$ Parece extremamente necessário delimitar algumas balizas à investigação da melancolia pelo método psicanalítico, pois permanece um problema teórico e clínico definir precisamente o que são as entidades psicopatológicas, melancolia e depressão, tanto na obra de Freud quanto no campo psicanalítico que o sucedeu.

No texto fundamental sobre o tema, "Luto e melancolia", Freud (1917[1915]): 275) apontava a existência de um problema de definição, uma vez que a melancolia assume várias formas clínicas cujo agrupamento em uma única unidade não parecia ter sido estabelecido com certeza, inclusive na psiquiatria descritiva. A definição do quadro clínico ali estabelecida por ele, é detalhada e única ao longo de sua obra, razão porque aqui está sendo considerada a definição freudiana por excelência. Em suas palavras:

Os traços mentais distintivos da melancolia são um desânimo profundamente penoso, a cessação de interesse pelo mundo externo, a perda da capacidade de amar, a inibição de toda e qualquer atividade, e uma diminuição dos sentimentos de autoestima a ponto de encontrar expressão em auto-recriminação e auto-envilecimento, culminando numa expectativa delirante de punição. Esse quadro torna-se um pouco mais inteligível quando consideramos que, com uma única exceção, os mesmos traços são encontrados no luto. A perturbação da auto-estima está ausente no luto; afora isso, porém, as características são as mesmas. (Ibid.: 276)

A importância de retomar a definição freudiana, deve-se a uma certa confusão que se estabeleceu no campo psicanalítico que o sucedeu. De fato, depois de Freud, Bleichmar (1983) já descreveu um deslizamento conceptual que implicou tomar a melancolia para nomear as psicoses e reservar o termo depressão para ocorrência dessa psicopatologia em quadros neuróticos. ${ }^{2}$ Entretanto, ainda considerando que se trata de uma descrição fenomenológica e sintomática, resta que circunscreve a problemática melancólica em uma direção precisa: a partir da hipótese freudiana da perda do objeto cuja sombra recobre o ego, dar-se-ão todos os desenvolvimentos posteriores.

Como se observa no trecho acima, Freud indica que também a psiquiatria não alcançou uma única definição de melancolia. Ele mesmo utiliza, ao longo de sua obra, melancolia, depressão, depressão melancólica, o mais das vezes como sinônimos, sem jamais estabelecer uma distinção clara entre os termos. De fato, ele tinha ambos

1. Este trabalho é parte da Tese de doutorado defendida na PUC-SP, em 2000, sob orientação do Prof. Dr. Manoel Tosta Berlinck.

2. Ver a respeito também Lambotte, M.C. O discurso melancólico: da fenomenologia à metapsicologia. 




os vocábulos disponíveis no alemão corrente, sendo que depressão chega ao alemão vindo do francês a partir do latim ${ }^{3}$ e, melancolia, é um velhíssimo termo de origem grega. ${ }^{4}$ Ora, inserido no debate de seu tempo como Freud era, não apenas ele pode ter tido contato com o termo depressão em sua estadia em Paris, como também não lhe escapava o uso cada vez maior que dele fazia a psiquiatria alemã, em deliberada substituição ao termo melancolia.

Realmente, foi Emil Kraepelin quem estabeleceu o uso do termo "insanidade maníaco-depressiva" na psiquiatria alemã. Como se sabe por um extenso estudo de Jackson (1985), em 1880, nas seções de psicoses de seu Lehrbuch, Kraepelin inicialmente usou insanidade depressiva para nomear uma das categorias de insanidade e incluiu uma forma depressiva como uma das categorias de paranóia, mas continuou a empregar melancolia e seus subtipos e a usar depressão principalmente para descrever afeto.

Ora, o renomado psiquiatra fez parte do contexto em que se desenvolvia a psicanálise e, além disso, contra ele Freud levantou-se em torno da questão do diagnóstico de insanidade maníaco-depressiva atribuído ao paciente conhecido como "Homem dos lobos". Portanto, quando se vê que Freud não apenas usa melancolia e depressão muitas vezes como sinônimos, mas prefere o termo melancolia nos textos em que formula as noções metapsicológicas fundamentais para dar conta do problema, não se pode deixar de pensar que a ele interessava demarcar um campo propriamente psicanalítico na psicopatologia.

Algo se passou para que os que o seguiram preferissem o termo depressão, Klein (1970) entre eles, já que, como se sabe, ela desenvolveu largamente uma concepção de depressão claramente derivada da freudiana, a ponto de chegar à noção fundamental de "posição depressiva" a partir da perda do objeto amado, como notou Hinshelwood (1992: 75). De fato, Klein, tendo se analisado com Abraham (1970), cujos estudos de melancolia também se estenderam até a chamada psicose maníacodepressiva e tiveram reconhecida importância já para Freud, também esteve sob forte influência da psiquiatria alemã, não tivesse ela buscado abrigo nos sanatórios de sua época até que veio a conhecer a psicanálise (Grosskurth, 1992). Parece haver, de fato, uma intencionalidade em fazer esquecer a melancolia, e aqui está mais uma indicação disso, novamente de Jackson (1985). Diz ele:

A tendência em se abandonar o termo melancolia e utilizar depressão pode ter sido especificamente favorecida por Adolf Meyer. O relato de uma discussão em 1904

3. Desse modo, está estabelecido que a depressão é impensável no mundo grego: Hipócrates, portanto, não poderia ter feito referência a depressão em suas formulações sobre melancolia.

4. Aqui ficamos devendo a Modesto Carone a análise da origem dos termos no alemão de Freud, a quem agradecemos de público. 


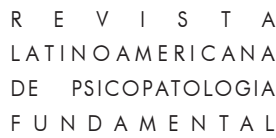

indica que ele desejava eliminar o termo melancolia, que implicava, segundo ele, em um conhecimento de algo que não possuíamos e, se ao invés de melancolia, aplicássemos o termo depressão para todas as classes, este indicaria, de uma forma simples, exatamente o que significava o termo melancolia. (p. 4-7)

Talvez seja preciso perguntar-se que interesse realmente clínico pode ter essa análise pelos meandros da história das idéias psicopatológicas. Ora, se a melancolia é velha conhecida da humanidade, os desenvolvimentos psiquiátricos e psicanalíticos posteriores a Freud, debruçando-se sobre o problema, tenderam a substituir o termo melancolia por depressão, no que resultou em se criar o que se pode chamar de invisibilidade da melancolia. No trecho acima, vê-se que Adolf Meyer declarou expressamente suas intenções. Essa invisibilidade tem resultado em fazer desaparecer traços distintivos da própria dinâmica psíquica dessa patologia. Nesse sentido, como observa Fédida (1996), a destrutividade e os sentimentos de culpa, que são tão evidentes na clínica orientada pelo método psicanalítico, acabam por desempenhar um papel menor no diagnóstico e, portanto, na elaboração das estratégias terapêuticas.

De fato, nesse campo teórico-clínico o problema de definição nosológica permanece em aberto ainda hoje, mesmo na psiquiatria clínica, como demonstrou Estevão (1997), em tese de doutorado defendida na Pós-Graduação do Hospital dos Servidores Públicos do Estado de São Paulo, que aqui se retoma a partir de um breve artigo, no qual se lê:

A prática clínica e a análise da literatura revelam a falta de critérios precisos para escolha do tratamento de depressão. (...) Em matéria de depressão, são debatidos, discutidos, controvertidos, todos os aspectos: nosologia, características sintomáticas, mecanismos bioquímicos, neurofisiológicos, terapêutica. Com toda boa vontade das "reuniões de consenso", as divergências persistem. É comum referir-se à heterogeneidade das manifestações para justificar a necessidade de mais reflexões e pesquisas. (...) diante desta situação, temos que registrar o mal-estar dos autores, quando constatam que 30 anos de pesquisas, não nos permitiram registrar autênticos progressos na terapia. Apesar das novas descobertas em neurobiologia e genética molecular, não temos nenhum teste de laboratório, nem marcador de doença válido. $\mathrm{O}$ estudo da imipramina feito por Khun, que hoje seria criticado pelas suas falhas metodológicas, delineou o tratamento da depressão em vigor até agora. Desde os anos 1950, comparando com estas importantíssimas descobertas, nada de qualitativamente novo surgiu. $\mathrm{O}$ modo de investigação largamente utilizado em nossos dias, não conduziu a resultados positivos para a clínica, nem cientificamente, nem praticamente. (p. 71-84)

Observa-se, portanto, também na psiquiatria um afastamento da teoria freudiana da melancolia, o que certamente não cessa de produzir efeitos de invisibilidade. 


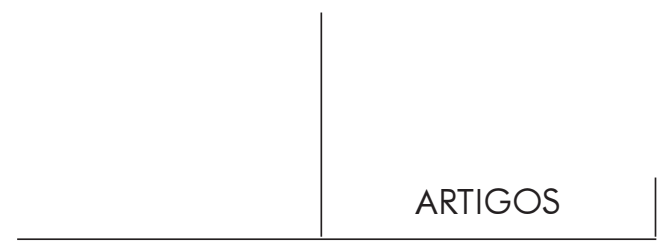

Édipo e melancolia

É de 1895 o "Manuscrito G”, em que Freud (1892-1899: 222) trata precisamente da melancolia, utilizando uma analogia que, aqui aparecendo pela primeira vez, será ainda extremamente frutífera. Ali se lê: "(a) $\mathrm{O}$ afeto correspondente à melancolia é o luto - ou seja, o desejo de recuperar algo que foi perdido. Assim, na melancolia, deve tratar-se de uma perda - uma perda na vida pulsional" ${ }^{5}$ Como se vê, já está aí uma primeira formulação daquela que será, até o fim de sua obra, a tese freudiana fundamental, isto é, de que na melancolia trata-se de "algo que foi perdido". O enigmático aqui é que a perda é na vida pulsional, enquanto na formulação posterior, a de "Luto e melancolia", há uma perda objetal que se transformou numa perda do ego, o que aponta, novamente, a importância da noção de narcisismo para esta investigação.

Entretanto, este breve ensaio, o "Manuscrito G", provavelmente seja de janeiro de 1895, anterior, portanto, à dolorosa ocorrência que Freud (1900: 32) reputará como "a perda mais pungente da vida de um homem". Logo, observa-se que a perda está presente nas idéias de Freud sobre a melancolia antes da morte de seu pai, mas só após esta é que não apenas cria a psicanálise, como a melancolia passa a ser inserida no eixo do complexo de Édipo. ${ }^{6}$

No "Manuscrito N", dirigido ao mesmo destinatário, encontra-se o texto em que Freud, pela primeira vez, insere a melancolia naquilo que será para ele até o fim, o eixo fundamental de toda análise que se pretenda psicanalítica. O complexo de Édipo, queiram ou não os psicanalistas, é o eixo estruturante de toda concepção freudiana do humano, assim como pelo lado da filogênese, é o mito científico do parricídio na horda primitiva que cumpre este papel. Essa importante e enigmática formulação o parricídio associado à melancolia - surge, pela primeira, vez sob a pena de Freud, no trecho intitulado "Impulsos (2)", dentro de "Notas III (Rascunho N)". Ali se lê:

Os impulsos hostis contra os pais (desejo de que eles morram) também são um elemento integrante das neuroses. Vêm à luz, conscientemente, como idéias obsessivas. Na paranóia, o que há de pior nos delírios de perseguição (desconfiança patológica dos governantes e monarcas) corresponde a esses impulsos. Estes são recalcados nas ocasiões em que é atuante a compaixão pelos pais - nas épocas de doença ou morte deles. Nessas ocasiões, constitui manifestação de luto uma pessoa acusar-se da morte

5. Carta datada provavelmente de 7 de janeiro de 1895. Ver também Masson, J.M. A correspondência completa de Sigmund Freud para Wilhelm Fliess, p. 99. Grifado no original.

6. De fato, a psicanálise, como todos sabem, nasce do sofrimento psíquico desencadeado pela morte de seu pai, como elemento determinante mas, claro, não exclusivo. Veja-se, a propósito, a análise de Mezan, segundo quem essa origem se dá sobre tríplice eixo: a clínica das neuroses, a análise da cultura e sua auto-análise. Cf. R. Mezan - O pensador da cultura. 


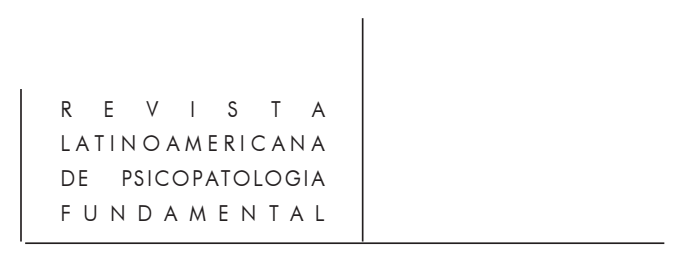

deles (o que se conhece como melancolia) ou punir-se numa forma histérica (por intermédio da idéia de retribuição) com os mesmos estados [de doença] que eles tiveram. A identificação que aí ocorre, como podemos verificar, nada mais é do que um modo de pensar, e não nos exime da necessidade de procurar o motivo.

Parece que esse desejo de morte, no filho, está voltado contra o pai e, na filha, contra a mãe...

Ora, o que está contido neste trecho, que Freud dará forma definitiva apenas em 1927, trinta anos depois, é a questão do parricídio, problema central em toda neurose. O que aí se coloca, e que torna a melancolia tão grave, é que, sendo culpado pela morte dos pais (e acusar-se significa culpar-se, ambos vêm da mesma raiz latina), a lei do talião, Freud já o dizia, cobra - olho por olho, dente por dente - a morte do sujeito, não o mero adoecimento como na histeria, nem a acusação dirigida a outrem, como na paranóia, tampouco o interminável sofrimento obsessivo, que ainda é uma forma de sobrevivência. Este trecho apresenta ainda outro problema que não será tratado neste trabalho - a hipótese freudiana do matricídio, um tema extensamente tratado por Stein (1988).

$\mathrm{Na}$ clínica, diante de um melancólico que demanda uma escuta para seu sofrimento, há uma espécie de urgência que invade o analista e uma hesitação, uma vaga expectativa do pior, uma espera que parece necessária, diante daquilo que se apresenta como algo inominável pairando. Uma hesitação diante da urgência, uma espécie de vertigem análoga àquela que pode ocorrer quando se está diante de um abismo perigoso à frente e a sensação física é dada pela própria lei da gravidade: um empuxo para baixo criando imediatamente a hesitação diante do perigo e a urgência de proteção. Estar com um paciente melancólico é, assim, hesitação e urgência. Algo ali precipita-se no vazio e a parceria entre paciente e analista fica premida pela busca de salvação, um desejo que o analista precisa reconhecer para avaliar seus matizes e consequiências na condução da análise.

\section{Superego e parricídio}

Em um trabalho de grande fôlego, Marta Gerez-Ambertin (1993: 17-36) realiza uma sistematização rigorosa da noção de superego na clínica psicanalítica e na cultura, a partir da obra de Freud e Lacan, uma contribuição muito bem-vinda pois sem dúvida há muito era necessária nesse campo. Dizendo de modo muito breve, ela apontou que, já desde o nascimento da psicanálise pode encontrar-se a tríade: parricídio, culpa e punição, tanto na teoria como na clínica dos primeiros casos de Freud. Segundo ela, ainda que tenha recebido seu nome de batismo em 1923, os fundamentos teóricoclínicos do superego já estão traçados ao redor desse tríplice eixo, e a noção de consciência moral é a expressão mais primitiva do superego. 


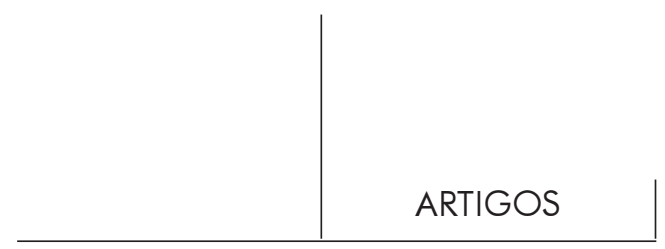

A idéia, desenvolvida por Gerez-Ambertin de que a temática "parricídio, culpa e punição" está subjacente a toda teoria psicanalítica torna-se ainda mais nítida ao pensar a melancolia, na qual tais temas são absolutamente decisivos, ajudando a compreender seus mecanismos de origem. Veja-se, a seguir, algumas indicações a partir dos textos freudianos.

A primeira evidência mais extensa aparece num pequeno texto de 1916, "Alguns tipos de caráter encontrados no trabalho psicanalítico" elaborado, portanto, pouco depois do clássico sobre o tema. Ali se lê:

Em outra ocasião, defrontei-me com o caso de um respeitável senhor, professor universitário, que nutria havia muitos anos o desejo natural de ser o sucessor do mestre que o iniciara nos estudos. Quando esse professor mais antigo se aposentou e os colegas informaram ao pretendente que ele fora escolhido para substitui-lo, começou a hesitar, depreciou seus méritos, declarou-se indigno de preencher o cargo para o qual fora designado, e caiu numa melancolia que o deixou incapaz de toda e qualquer atividade durante vários anos. (p. 358)

Mas será preciso esperar ainda longos anos até que, em 1922, a temática do parricídio na melancolia tomasse forma metapsicológica. Em "Uma neurose demoníaca do século XVII" (1923[1922]), Freud encontra na morte do pai do pintor Haizmann a origem de sua melancolia, que o leva a complicados pactos com o demônio com o fim de que este constitua, afinal, um substituto paterno. Ali encontrase um trecho fundamental para este argumento. Em suas palavras:

Foi por isso que, no início deste artigo, predisse que um caso clínico de demonologia desse tipo produziria, sob a forma de metal puro, um material que nas neuroses de uma época posterior (não mais supersticiosas, mas antes hipocondríacas) tem de ser laboriosamente extraído, pelo trabalho analítico, do minério das associações livres e dos sintomas. Uma penetração mais profunda na análise da moléstia de nosso pintor provavelmente trará uma convicção mais forte. Não é algo fora do comum para um homem adquirir uma depressão melancólica e uma inibição em seu trabalho, em resultado da morte do seu pai. Quando isto acontece, concluímos que o homem fora ligado ao pai por um amor especialmente intenso e recordamos com quanta frequiência uma melancolia grave surge como forma neurótica de luto. (p. 111-112)

Se nesse texto nenhuma referência ao sentimento inconsciente de culpa, que já havia sido postulado, pode ser encontrada, a ambivalência, traço melancólico como se sabe, não lhe escapa, e Freud irá dizer que a própria atitude hostil contra o pai, que é uma atitude de odiá-lo, temê-lo e fazer queixas contra ele, ganha expressão na criação mesmo de Satã e um anseio pelo pai aliado a uma extrema necessidade material, como determinantes de sua neurose, são postulados. Encontra-se, portanto, a melancolia inserida no campo da neurose, como forma patológica de luto, um 


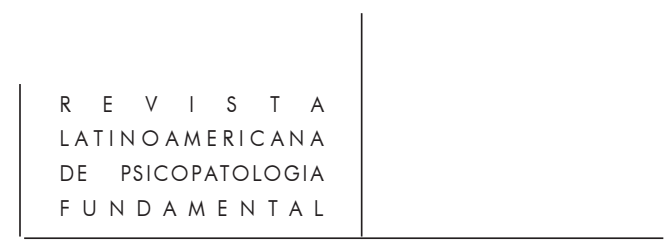

desenvolvimento da concepção contida em "Luto e melancolia" e, ao mesmo tempo, prenúncio do que virá a seguir.

Em "Neurose e psicose", texto logo posterior, concluído em 1923, Freud (1917[1916-17]) propõe que a melancolia se inclui entre as neuroses narcísicas, mas que se trata de um conflito entre o ego e o superego. Essa formulação, anunciada aqui como hipótese, será investigada e sustentada até o fim de sua obra e contém uma oposição expressa a incluí-la no campo das psicoses, como havia feito anteriormente, sustentando que estas últimas correspondem a um conflito entre o ego e a realidade.

Finalmente, Freud afirmava em "Psicopatologia da vida cotidiana" (1901) que é difícil para o psicanalista descobrir algo que já não saiba algum escritor e em sua inabalável coerência, dirigiu-se a um deles, para, uma vez mais, investir em decifrar o enigma. Será em "Dostoiévski e o parricídio" (1928[1927]) que formulará o essencial de sua concepção, definindo a melancolia desse grande autor como derivada de desejos parricidas que nele permaneceram sem [des]culpa, isto é, sem elaboração. Em suas palavras:

Dispomos de um ponto de partida seguro. Conhecemos o significado das primeiras crises que Dostoiévski sofreu em seus primeiros anos, muito antes da incidência da "epilepsia". Essas crises tinham a significação de morte; eram anunciadas por um temor da morte e consistiam em estados sonolentos, letárgicos. A moléstia o acometeu pela primeira vez quando ainda menino, sob a forma de uma melancolia súbita e infundada, uma sensação, como mais tarde contou a seu amigo Soloviev, de que iria morrer ali mesmo. (...) Conhecemos o significado e a intenção dessas crises semelhantes à morte. Significam uma identificação com uma pessoa morta, seja com alguém que está realmente morto ou com alguém que ainda está vivo e que o indivíduo deseja que morra. O último caso é o mais significativo. A crise possui, então, o valor de uma punição. Quisemos que outra pessoa morresse; agora somos nós essa outra pessoa e estamos mortos. Nesse ponto, a teoria psicanalítica introduz a afirmação de que, para um menino, essa outra pessoa geralmente é o pai, e de que a crise (denominada de histérica) constitui assim uma autopunição por um desejo de morte contra um pai odiado.

O parricídio, de acordo com uma conceituação bem conhecida, é o crime principal e primevo da humanidade, assim como do indivíduo. (...) É, em todo caso, a fonte principal do sentimento de culpa, embora não saibamos se a única; as pesquisas ainda não conseguiram estabelecer com certeza a origem mental da culpa e da necessidade de expiação. (p. 211)

Freud afirma, no excerto acima, que a melancolia de Dostoiévski é resultado de seu desejo parricida, uma autopunição pelo desejo de morte contra um pai odiado. Neste trecho, tem-se claramente formulada a idéia de que este desejo é a fonte principal do sentimento de culpa que, permanecendo atuante, conduz à melancolia.

Em uma psicoterapia conduzida no contexto de um serviço público de saúde, encontrei um paciente cuja visível melancolia achou, no cenário da epidemia de Aids, 


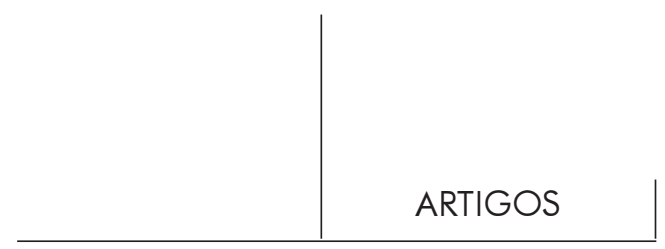

o personagem que faltava para completar seu romance familiar. Perdido o companheiro, levado pela síndrome, a identificação que resultou desse luto não elaborado, narcísica em sua origem, deu lugar ao desejo de morte manifesto com cruéis auto-acusações e sentimentos de culpa, e as fantasias parricidas resultaram atuadas em lenta agonia que acabou por consumi-lo.

Chegando ao final desta exposição, penso que esteja ao menos delineada a hipótese para os problemas de definição que ainda permanecem, longos anos depois de Freud. De fato, parece que a hesitação em encarar a temática do parricídio até suas últimas conseqüências é o que tem obstaculizado novos desenvolvimentos nessa área, não fosse a invisibilidade uma boa forma de se defender do inominável cuja sombra, a melancolia, segue projetando.

\section{Referências}

Abraham, Karl (1927). Teoria psicanalítica da libido. Rio de Janeiro: Imago, 1970.

Bleichmar, H.B. Depressão: um estudo psicanalítico. Porto Alegre: Artes Médicas, 1983.

Estevão, G. Do diagnóstico da depressão e suas implicações terapêuticas. In Temas, n. 53, p. 71-84, 1997.

FÉdidA, P. O sítio do estrangeiro. A situação psicanalítica. São Paulo: Escuta, 1996.

Freud, S. (1892-1899). Extratos dos documentos dirigidos a Fliess. ESB. Rio de Janeiro: Imago, 1980. v. I. (1900). A interpretação dos sonhos. ESB. Op. cit. v. IV. (1901). Psicopatologia da vida cotidiana. ESB. Op. cit. v. VI. (1914). Sobre a introdução do conceito de narcisismo. ESB. Op. cit. v. XIV. (1916). Alguns tipos de caráter encontrados no trabalho psicanalítico. ESB. Op. cit. v. XIX. (1917[1915]). Luto e melancolia. ESB. Op. cit. v. XIV.

(1917[1916-17]). Conferência XXVI: A teoria da libido e o narcisismo. ESB. Op. cit. v. XVI.

(1923[1922]). Uma neurose demoníaca do século XVII. ESB. Op. cit. v. XIX. (1924[1923]). Neurose e psicose. ESB. Op. cit. v. XIX. (1928[1927]). Dostoiévski e o parricídio. ESB. Op. cit. v. XXI.

Gerez-Ambertin, M. Las voces del superyo. En la clínica psicoanalítica y en el malestar en la cultura. Buenos Aires: Manantial, 1993.

GrosskuRth, P. O mundo e a obra de Melanie Klein. Rio de Janeiro: Imago, 1992.

Hinshelwood, R. D. Dicionário do pensamento kleiniano. Porto Alegre: Artes Médicas, 1992.

JaCkson, S. Melancholia \& Depression. From Hippocratic Times to Modern Times. London: Yale University Press, 1985.

KLeIn, M. A Contribuition to the Psychogenesis of Manic-Depressive States, L. 1935. 
Lambотте, M.C. O discurso melancólico: da fenomenologia à metapsicologia. Rio de Janeiro: Companhia de Freud, 1997.

Masson, J. M. A correspondência completa de Sigmund Freud para Wilhelm Fliess 1887-1904. Rio de Janeiro: Imago, 1986.

Mezan, R. Freud - O pensador da cultura. São Paulo: Brasiliense, 1985.

Stein, C. As Erínias de uma mãe: ensaio sobre o ódio. São Paulo: Escuta, 1988.

\section{Resumos}

Este trabajo presenta la problemática de definición de la melancolía, examinada a partir de la obra freudiana en la cual ella ya está indicada desde el texto: "Luto y Melancolía" (1917). La abordaje de la concepción freudiana conduce al examen de los principales textos en que ésta es formulada como una neurosis narcísica, derivada del recrudecimiento del conflicto edípico y envolviendo las fantasías de parricidio e incesto, a partir de una pierda objetable retirada de la conciencia.

Palabras clave: Melancolía, depresión, narcisismo, parricidio

Ce travail présente la problématique de définition de la mélancolie, examinée à partir de l'oevre freudienne, où elle figure dés "Deuil et mélancolie" (1917). L'abordage de la conception freudienne conduit à l'examen des principaux textes où la mélancolie est formulée comme une névrose narcissique dérivée de la recrudescence du conflit oedipien impliquant les fantasmes parricides et incestueux, ceci à partir d'une perte objectale retirée, exclue de la conscience.

Mots clés: Mélancolie , dépression, narcissisme, parricide

This paper discusses the problem of defining melancholia, based on Freud's "Mourning and melancholia" (1917). An analysis of Freud's conception leads the reader to an examination of the main texts where this concept is formulated as a narcissistic neurosis caused by a return of the Oedipal conflict and involving phantasies of parricide and incest caused by an object loss that has been removed from consciousness.

Key words: melancholy, depression, narcissism, parricide

Versão inicial recebida em fevereiro de 2001

Versão aprovada em novembro de 2001 